DOI: http://dx.doi.org/10.22484/2177-5788.2016v42n2p365-374

\title{
Reflexões sobre os povos vulneráveis como produtores de violência
}

\author{
Luciana Coutinho Pagliarini de Souza
}

Resumo: Num contexto em que as populações vulneráveis são tema, este artigo traz a violência que se instala nesse universo como foco. O corpo esquartejado/decapitado representado nas artes plásticas pela Medusa, no cinema por 'Le mélomane' de Georges Méliès (1903) e no jornal Folha de S.Paulo por imagens da rebelião na prisão de Pedrinhas/MA1, constitui o objeto desse artigo. Refletir sobre as formas subjetiva e simbólica da violência, a partir da tipologia instituída por Zizek, é nosso propósito. Para tanto, apresentam-se reflexões sobre o excluído ou o estranho enquanto produtor de violência, sobre a violência produtora do choque como mote das representações visuais que se fazem corpus. A importância deste artigo está na possibilidade de trazer à tona discussões sobre um fenômeno que permeia nosso cotidiano.

Palavras-chave: Povos vulneráveis. Violência. Representações visuais midiáticas.

\section{Reflections about vulnerable peoples as violence producers}

Abstract: Within a context in which vulnerable populations are the theme, this article brings the violence that sets in this universe as a focus. The dismembered/beheaded body represented in the plastic arts by Medusa, in the cinema by Georges Méliès' Le Mélomane (1903) and in the newspaper Folha de S. Paulo by images of the rebellion in the prison of Pedrinhas/MA [1], constitutes the object of this article. Reflecting on the subjective and symbolic forms of violence, based on the typology established by Zizek, is our purpose. Thereto, one presents reflections either on the excluded or the strange as violence producer, on the violence that produces the shock as a motto of the visual representations that become corpus. The importance of this article lies in the possibility of bringing up discussions about a theme that permeates our daily life.

Keywords: Vulnerable people. Violence. Visual representations of the media. 


\section{Introdução}

A violência que se instala no universo das populações vulneráveis é foco deste artigo. Começamos por divisar as formas de violência a partir de Zizek (2014) a subjetiva e a objetiva. Ao lado dessa tipologia, também as violências mítica e a divina preconizadas por Benjamin ganham espaço.

A partir de Bauman, caracterizamos os protagonistas da violência sobre a qual refletimos: o resultado de um motim que resultou na decapitação de três detentos do complexo de Pedrinhas, no Maranhão filmado por um celular. A opção por esse episódio e não pelos mais recentes ocorridos em prisões de Natal (RN), Manaus (AM) e Rondônia (RN), que deram mostra de uma certa "naturalização da barbárie", deu-se pelo fato de ser inaugural de nova prática: foi o primeiro a ser filmado pelos celulares dos presos e divulgado pela internet. Adentramos assim o universo paralelo habitado pelos "estranhos" concebidos por este teórico.

A simbologia da cabeça na cultura celta, na mitologia (Medusa), no cristianismo (João Batista), representada nas artes visuais; a manifestação do sagrado, do sobrenatural e mágico no jogo de cabeças representada no cinema por Méliès vem alimentar o imaginário que esta prática suscita. A violência a que se assiste num cenário habitado por “estranhos” é, finalmente, discutida a partir das tipologias apresentadas.

\section{Sobre a violência}

A violência, aos olhos de Zizek, se constitui de duas vertentes: a subjetiva e a objetiva. A mais visível, exercida por agentes identificáveis e reconhecíveis por meio de atos de horror, é a denominada subjetiva. Tal é sua força, que deixamos de compreender que ela é "somente a parte mais visível de um triunvirato que inclui também dois tipos objetivos de violência" (ZIZEK, 2014, p. 17).

Esta outra vertente anunciada, a violência objetiva, "é experimentada enquanto tal contra o pano de fundo de um grau zero de violência" (ZIZEK, 2014, p. 17). Caracteriza-se como perturbação da ordem estabelecida, do funcionamento do cotidiano, mas é invisível e se desdobra em outras facetas: a simbólica e a sistêmica.

É sistêmica a violência objetiva que está inserida "naturalmente" em um sistema político, social, cultural, econômico, de tal modo a não se fazer ver. Ao desconsiderá-la, correse o risco de acreditar que a violência subjetiva é tão-somente explosão irracional. Ela age, de 
forma sutil, entranhada na dinâmica do capitalismo, na sustentação da relação de dominação e exploração. Trata-se de uma força coercitiva, anônima, que comanda o funcionamento da sociedade de modo a parecer natural, é percebida como "o jeito que as coisas são".

É simbólica a violência objetiva que se inscreve na linguagem. Zizek (2014, p. 59) lembra-nos que Benjamin considerava que a linguagem guarda em si "algo violento no próprio ato de simbolização de uma coisa, equivalendo a sua mortificação", à medida que nomear algo é revesti-lo de uma significação exterior a sua realidade imediata.

Zizek (2014) também traz à baila, para sua tipologia, outras formas de violência concebidas por Walter Benjamin (2013), a violência mítica e a divina. Tais conceitos se alicerçam na relação entre a força do direito exercida pelo Estado e a oposição ao excesso nesse exercício.

A violência mítica é uma forma arquetípica da manifestação dos deuses. Remete às incertezas e ambiguidades do destino atreladas às lendas da Antiguidade cujos heróis desafiavam o destino para trazer aos homens a instauração de um novo direito. "A instauração do direito é instauração do poder e, enquanto tal, um ato de manifestação imediata da violência. A justiça é o princípio de toda instauração divina de fins, o poder [Match] é o princípio de toda instauração mítica do direito" (BENJAMIN, 2013, p. 148).

Se a violência mítica é instauradora do direito, a violência divina é aniquiladora do direito. Se a primeira estabelece fronteiras, a segunda aniquila sem limites. Se a violência mítica traz, simultaneamente, culpa e expiação, a violência divina expia a culpa; se a primeira é ameaçadora, a segunda golpeia; se a primeira é sangrenta, a divina é letal de maneira não-sangrenta (BENJAMIN, 2013, p. 150).

Ao contrário da ideia assumida pela imprensa de se associar a violência divina às causas dos fundamentalistas, esta forma de violência "é a violenta explosão de ressentimento que encontra expressão neste espectro que vai dos linchamentos de massa ao terror revolucionado organizado" (ZIZEK, 2014, p. 146). Segundo Benjamin (2013, p. 249-50):

Assim como em todos os domínios Deus se opõe ao mito, a violência divina se opõe à violência mítica [...]. A violência mítica é violência sangrenta exercida, em favor próprio, contra a mera vida; a violência divina e pura se exerce contra toda a vida, em favor do vivente. A primeira exige sacrifícios, a segunda os aceita.

Zizek (2014) exemplifica a violência divina benjaminiana com as atitudes de Gandhi. Sem usar a força, ele conseguiu paralisar a dominação britânica, interferindo no funcionamento econômico e político da colônia. A reação do poder é o brutal pois ligada ao protecionismo. 
Outro exemplo de Zizek (2014, p. 157) ilustra uma passagem ocorrida no Rio de Janeiro, quando favelados invadem, em massa, bairros de classe alta, saqueando e incendiando supermercados. Os assaltantes correspondiam a "gafanhotos bíblicos", alegorias do castigo divino aos pecadores. Trata-se de uma decisão de matar ou morrer tomada sem a cobertura de Deus (ou do Grande Outro). Assim, quando os que se encontram fora do campo social estruturado atacam irrefletidamente, vindos do nada, clamando por justiça imediata: eis a violência divina.

Esse quadro tipológico da violência pode lançar luzes sobre nosso objeto: corpos esquartejados/decapitados de presos rivais filmados em um vídeo gravado no celular por presos amotinados na Penitenciária de Pedrinhas, no Maranhão. Chama atenção a frieza com que os assassinos cuidam da técnica da filmagem e como se divertem, exibindo os corpos ou o que restava deles.

Inscritos no universo de populações vulneráveis, os opressores e oprimidos deste contexto específico ocupam o território dos excluídos e marginais enquanto produtores de violência. Excluídos que são, constituem-se como o "outro", o estranho. Sobre eles recaem nossas próximas reflexões.

\section{O vulnerável ou "estranho" como agente da violência}

“Todas as sociedades produzem estranhos". Assim Bauman (1998, p. 27) inicia suas considerações sobre a criação e anulação dos estranhos, que aqui sustentam nossas reflexões. Cada sociedade produz um tipo peculiar e inimitável de estranhos ou "pessoas que não se encaixam no mapa cognitivo, moral ou estético do mundo" (p. 27). Ainda que trace suas fronteiras e delineie seus mapas cognitivos, estéticos e morais, a sociedade gera pessoas que se recusam a se enquadrar nesses limites, provocando assim a experiência do mal-estar. Os transgressores são os estranhos; o defensor, a fonte da vida ordeira é o estado.

Foi o estado que soube o que a ordem devia aparecer e que teve força e arrogância bastante não apenas para proclamar que todos os outros estados de coisas são a desordem e o caos, como também para obrigá-los a viver nessa condição. Foi este, em outras palavras, o estado moderno - que legislou a ordem para a existência e definiu a ordem como a clareza de aglutinar divisões, classificações, distribuições e fronteiras (BAUMAN, 2010, p. 28).

Nesse impasse entre o estado moderno e aqueles que não se ajustaram à sua organização, Bauman traz à baila duas estratégias alternativas, mas também complementares: a primeira, 
antropofágica ou estratégia de assimilação, que consistia em abater os estranhos e devorá-los, de modo a apagar as diferenças culturais, sociais, linguísticas e garantir a conformidade com a ordem; a segunda, antropoêmica ou estratégia de exclusão, que consistia em 'vomitar' os estranhos, expulsando-os para além das fronteiras. Se nenhuma das estratégias resolvesse, a saída era destruí-los fisicamente. Esse era o projeto da modernidade.

A época atual, contudo, caracteriza-se pela indiferença do estado na tarefa de promover a ordem, ao mesmo tempo em que se percebe uma falta de interesse em organizar a desordem do mundo. Os estranhos na sociedade pós-moderna são preferencialmente banidos do mundo ordeiro para guetos e proibições de contato chegando à sua aniquilação cultural e física. No mundo ordeiro residem os que pagam para serem respeitados: moram bem, trabalham em escritórios fortificados e seguros, fazem escolhas, podem usar a liberdade de consumidor; do outro lado, os excluídos da vida econômica e social, os rotulados como "classes perigosas" e "consumidores falhos". São estes últimos os que alimentam a "indústria da prisão". É nesse nicho de vulneráveis em que se encontram os protagonistas do vídeo em que nos debruçamos nesse trabalho.

À primeira vista, a violência subjetiva é a que eclode do ato de barbárie e selvageria que divisamos, mas o que dizer da performance que se apresenta nas imagens videográficas? As formas de violência que subjazem à violência subjetiva, além das preconizadas por Benjamin a mítica ou sagrada - receberão a seguir nosso olhar.

\section{A cabeça como símbolo da violência mítica}

A prática da decapitação é prenhe em nosso imaginário. Para ficar no âmbito das representações visuais, tal como o vídeo filmado pelos presidiários de Pedrinhas, resgatamos o mito da Medusa representado pelas artes plásticas, o sagrado nas imagens cinematográficas da cabeça de João Batista numa bandeja oferecida a Salomé, bem como ‘Le mélomane' de Georges Méliès (1903).

Para Chevalier e Gheerbrant (2008, p. 151), a cabeça geralmente simboliza o ardor de princípio ativo. Abrange a autoridade de governar, ordenar instruir [...]. Devido à sua forma esférica, a cabeça humana é comparável, segundo Platão, a um universo. É um microcosmo. Para muitos povos, a cabeça possui grande valor. No mundo celta, a cabeça é objeto de muitas práticas e crenças, sobretudo nas guerras. Os gauleses cortavam as cabeças dos inimigos 
vencidos e as conservavam como troféus que simbolizavam a incorporação ao vencedor da força e do valor do guerreiro vencido. Entre determinados povos indígenas, a cabeça dos inimigos era diminuída e cultuada. Também na literatura judaico-cristã, a cabeça de João Batista pedida por Salomé ilustra a prática da decapitação e a simbologia da cabeça para os povos antigos.

Representada na pintura por Caravaggio, a figura mítica da Medusa (figura 1) se distingue na cultura grega. Mesmo depois de decepada por Perseu, a cabeça da górgona mantinha o poder de petrificar os que para ela olhassem. Dentre os muitos significados da cabeça da Medusa, destacamos o uso que Perseu faz dela ao derrotar o monstro marinho enviado para matar Andrômeda, a princesa que amava e a petrificação de seu noivo. Essa atitude marca o ritual de passagem de Perseu para a vida adulta, tornando-o apto ao poder régio (ZIERER, 2011).

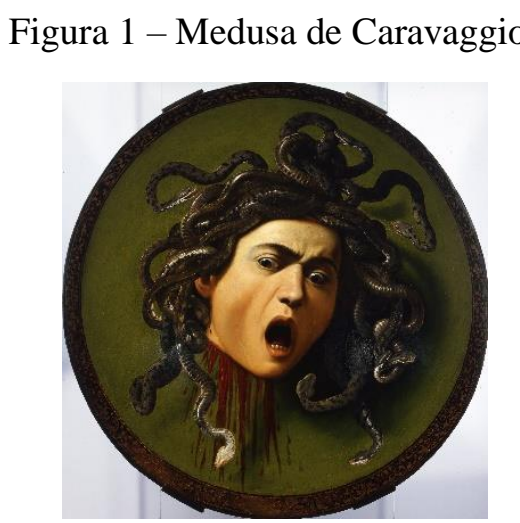

Fonte: Medusa. Disponível em <https://en.wikipedia.org/wiki/Medusa_(Caravaggio)>. Acesso em: 15 jan. 2016.

Outra analogia relacionada com a cabeça é a que a torna sede da alma. Tanto os celtas como os pitagóricos acreditavam que, enquanto sede da alma, ela poderia se perpetuar em outros corpos. De modo geral, segundo Zierer (2011), a cabeça está associada a dois fatores: à guerra pelo poder transmitido àquele que a possuísse; à sacralidade, devido à crença de que ela gerava vida e encarnava outros corpos.

Também no cinema, a cabeça cortada teve várias representações. Desde o período do Primeiro Cinema, o desejo de se representar visualmente as manifestações do sagrado já ocorria. Os experimentos de Méliès, por exemplo, faziam com que objetos e pessoas aparecessem e desaparecessem. Nessas primeiras experiências, prevaleceram as representações visuais cujo sentido do espantoso e do senso de espetacular era a exploração das potencialidades 
do novo meio, permitindo a visão de coisas impossíveis de ocorrerem na realidade cotidiana (figura 2).

Figura 2 - O jogo de cabeças.

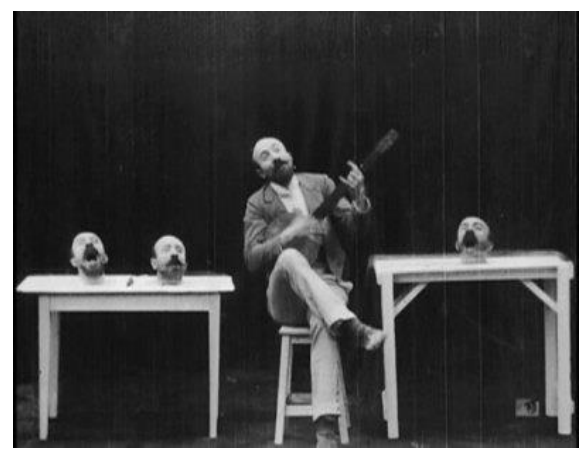

Fonte: The Magic of Méliès (1898 - 1909). Disponível em https://javiuesse.files.wordpress.com/2013/02/themagic-of-mc3a9lic3a8s-cena.jpg>. Acesso em: 15 jan. 2016.

A partir dessas primeiras experiências, podemos facilmente estabelecer relações com as ideias de mágico, fantástico e sobrenatural. Ora, todas estas ideias parecem se relacionar diretamente com o fato de que tais coisas são impossíveis e que as leis da natureza parecem ter sido derrogadas naquele momento. Isto não quer dizer uma relação direta com a ideia de sagrado, mas sim, isto quer dizer uma relação direta com o método, com a tecnologia que permite representar este momento que de outra forma não pode ser percebido no mundo natural. As cabeças que rolaram em Pedrinhas, que simbologia carregam? E que formas de violência se depreendem dessa selvageria?

Segundo descrição de Scolese (2014), os dois minutos e 32 segundos de filmagem têm início com a ordem "Tem que ajeitar o foco". Em movimento pela penitenciária, um dos amotinados - em torno de meia dúzia - dirige a câmera para o chão molhado de água e sangue, de modo que apenas os pés dos participantes da filmagem aparecem. No décimo segundo do vídeo, finalmente o saldo do motim é revelado: diante das câmeras os corpos de três detentos degolados.

Em tom de comemoração, as cabeças são dispostas nos corpos dos presos, ora puxadas pelos cabelos em meio a comentários: "Bota de frente pra filmar direito" ... "Não puxa a cabeça dele" ... Nas costas de um dos corpos, duas cabeças, lado a lado, são exibidas como troféu. Um dos presos coloca o pé sobre um dos corpos em sinal de domínio. Ao aproximar-se das cabeças, a câmera flagra marcas de tortura nas faces. Já ao final do vídeo, um dos presos pega uma das cabeças, gira-a em direção à câmera e grita "Filma aí esse maldito desgraçado", enquanto outro 
pede "Vira de lado, vira de lado...". E assim, diante da breve e pesada descrição, nos defrontamos com a selvageria da violência subjetiva. Ainda que apareçam de forma metonímica no vídeo, os responsáveis pela chacina são facilmente identificáveis.

Considerando-se que a violência simbólica está impressa na linguagem e está presa a um universo de sentido e, ainda, levando-se em conta que a imagem constitui-se como linguagem, a cabeça nesse contexto de uma sociedade paralela - um microcosmo -, em que a disputa pelo poder é garantia de sobrevivência - daí a selvageria - os sentidos estão voltados para o primeiro fator com a qual se associa: a guerra. O jogo do poder, do domínio, tem na cabeça o maior prêmio, o troféu.

As duas cabeças sobre o corpo de um dos detentos que ainda mantinha a cabeça rente ao pescoço remete-nos à figura mítica de Cérbero, cão de três cabeças que guardava a porta do inferno.

A outra face da violência objetiva, a sistêmica, se faz presente na própria estrutura do sistema econômico, político e, mais especificamente, no caótico funcionamento do sistema carcerário. O complexo de Pedrinhas abrigava, na época, 2.200 presos para 1.700 vagas. Situação que não destoa dos outros presídios do Brasil, abandonados pelo poder público. Tais condições criam, automaticamente, "excluídos e dispensáveis", os estranhos marginalizados.

Ao contrário da violência divina preconizada por Benjamin, o que se verifica é a violência mítica exercida em favor próprio, contra a vida. Não há qualquer propósito que justifique a violência divina, cujo ato converge em favor do vivente.

Finalmente, na tipologia de Bauman, nem a estratégia da antropofagia nem a de antropoêmica abarcam o ato descrito. Nem se assimila o outro, apagando diferença, nem se afasta o outro do convívio, expulsando-o para além das fronteiras. O que se vislumbra é a destruição física.

\section{Considerações finais}

A violência, de maneira recorrente, está presente no cotidiano e é veiculada, de forma privilegiada, em todas as mídias. Isso não a torna tema banal, pelo contrário, são inquietantes as situações que dela se impregnam, daí interpelarem as nossas reflexões.

A situação retratada nesse artigo que traz como temática populações vulneráveis - o motim ocorrido na cadeia de Pedrinhas, em São Luiz (MA) - trouxe dois fatos dignos de serem 
discutidos pelo que representam no desvio da ordem civil estabelecida: a decapitação de três presos e o registro em vídeo dessa barbárie para ser postado em rede social.

A decapitação está presente no sagrado e reverbera no mito via artes plásticas, cinema, produtos culturais delimitados nesse artigo. Enquanto território do simbólico, carrega como sentido histórico a barbárie e como metáfora a privação do poder.

Voltando-nos para nosso objeto - a decapitação ocorrida em Pedrinhas - e levando em conta a tipologia da violência desenvolvida por Zizek, que, por sua vez, incorpora a classificação pensada por Benjamin, chegamos a algumas conclusões.

Tais violências não são estanques. Subjacente à violência subjetiva, estão os contornos dos cenários que engendram as explosões de fúria dadas pela violência objetiva. Instala-se nesta última a violência simbólica que se encarna na linguagem - verbal/visual - e em suas formas e vai muito além dos discursos habituais de provocação ou de relações de dominância, ela está introjetada na linguagem enquanto tal e sujeita à imposição de um certo universo de sentido.

Também subjacente à violência subjetiva está a objetiva sistêmica que, nas palavras de Zizek (2014, p. 17), “consiste nas consequências muitas vezes catastróficas do funcionamento regular de nossos sistemas econômico e político". Ela é própria das condições sociais do capitalismo global que implica a criação "automática" de indivíduos excluídos e dispensáveis, dos sem-teto, favelados, desempregados (p. 26)

Se de um lado a violência subjetiva só é notada enquanto perturbadora da ordem e da normalidade; de outro lado, a violência objetiva é inerente ao estado "normal" das coisas. Sua invisibilidade a torna imperceptível na sustentação do "grau zero de violência" em que desponta a subjetiva. Ou seja, é preciso adentrar essa camada subjacente aos atos explosivos para tentarmos racionalizar o que, aparentemente, é pura explosão irracional.

Os pertencentes ao outro lado, os excluídos da vida econômica e social, os rotulados como "classes perigosas" e "consumidores falhos" são os que alimentam a "indústria da prisão". É nesse nicho de vulneráveis que se encontram os protagonistas do vídeo em que nos debruçamos nesse trabalho. E o que dizer a respeito, sem que isso soe como um discurso protecionista ou que justifique a barbárie como forma legitima de negação do estabelecido? Nas entrelinhas da violência subjetiva subjaz o sistema que tece "naturalmente" relações que reforçam a exclusão inscritas na política, educação, economia. Subjaz ainda a violência simbólica na referência feita na gravação do vídeo aos "malditos desgraçados". 
Finalmente, a violência mítica benjaminiana é revisitada na prática desses excluídos ou "estranhos". A cabeça como troféu impregnada de poder e glória "coroa" e institui uma nova ordem.

\section{Referências}

BAUMAN, Zygmunt. O mal-estar da pós-modernidade. Rio de Janeiro: Jorge Zahar, 1998.

BAUMAN, Zygmunt. Vida a crédito. Rio de Janeiro: Jorge Zahar, 2010.

BENJAMIN, Walter. Escritos sobre mito e linguagem. São Paulo: Duas Cidade; Editora 34, 2013.

BENJAMIN, Walter. A obra de arte na era de sua reprodutibilidade técnica. Porto Alegre: L\&PM, 2013.

CHEVALIER, Jean; GHEERBRANT, Alan. Dicionário de símbolos. Rio de Janeiro: José Olympio, 2008.

SCOLESE, E. Presos filmam decapitados em penitência do Maranhão: veja vídeo. Folha de S. Paulo, São Paulo, 07 jan. 2014. Cotidiano. Disponível em:<

http://www1.folha.uol.com.br/cotidiano/2014/01/1394160-presos-filmam-decapitados-em-

penitenciaria-no-maranhao-veja-video.shtml .

ZIERER, Adriana. Simbologia da cabeça cortada entre os celtas e algumas analogias com o mito da górgona. PHOINIX, Rio de Janeiro, v.17, n. 1, p. 112-129, 2011.

ŽIŽEK, Slavoj. Violência: seis reflexões laterais. São Paulo: Boitempo, 2014.

Luciana Coutinho Pagliarini de Souza - Universidade de Sorocaba - Uniso | Sorocaba | São Paulo. Contato: luciana.souza@prof.uniso.br 